\title{
VALIDATION OF DOSE CALCULATION CODES FOR CLEARANCE
}

\author{
Shankar Menon \\ Menon Consulting, Sweden \\ Bo Wirendal \\ Studsvik RadWaste, Sweden \\ Jan Bjerler \\ Studsvik Stensand, Sweden \\ Lucien Teunckens \\ Belgoprocess, Belgium
}

\begin{abstract}
Various international and national bodies such as the International Atomic Energy Agency, the European Commission, the US Nuclear Regulatory Commission have put forward proposals or guidance documents to regulate the "clearance" from regulatory control of very low level radioactive material, in order to allow its recycling as a material management practice. All these proposals are based on predicted scenarios for subsequent utilisation of the released materials. The calculation models used in these scenarios tend to utilise conservative data regarding exposure times and dose uptake as well as other assumptions as a safeguard against uncertainties.
\end{abstract}

None of these models has ever been validated by comparison with the actual real life practice of recycling. An international project was organised in order to validate some of the assumptions made in these calculation models, and, thereby, better assess the radiological consequences of recycling on a practical large scale.

The validation was proposed to be carried out by comparing the results of dose measurements during a chain of recycling operations to dose values calculated for the same operations using the (US) RESRAD-RECYCLE and the (French) CERISE programmes. The operations were to cover all recycling activities, including the receipt of contaminated scrap at the radiologically controlled melting facility, its segmentation and melting, transport of released ingots to a manufacturing industry for use with other scrap as feed material and production of industrial products (rolls).

The project was initiated by the Swedish Radiation Protection Institute and was a co-operation between authorities, research institutes and commercial companies from Sweden, France, USA and Belgium.

A first phase of melting of contaminated scrap at Studsvik, release of ingots and transport to Åkers was carried out. The ingots were re-melted along with other (uncontaminated) scrap at Åkers to be used for manufacturing rolls. The doses to workers were measured at Studsvik, Åkers and during ingot transport. Dose calculations were made in parallel with these operations using the RESRAD-RECYCLE and CERISE programmes. However, the results of these calculations could not be compared with the corresponding values of doses taken by workers, because all of the doses were below the limit of detection.

Due to this fact, a second phase was executed involving the segmenting and melting of a $3.4 \mathrm{t}$ stainless steel fuel rack with an estimated activity concentration of over $150 \mathrm{~Bq} / \mathrm{g}$, mostly Co-60. 
The fuel rack was melted for volume reduction in the Studsvik facility in the middle of January 2001 , in the presence of project team including the dose modellers, who then made code calculations to estimate the dose uptake of the workers.

All personnel involved in the project operations were equipped with electronic (display) dosimeters. The measurements showed that segmenting was the work operation that gave the highest dose, almost $65 \%$ of the total dose incurred, while melting itself accounted for only about $13 \%$.

A comparison of the measured doses with corresponding calculation results indicated that, even with a carefully controlled reflection of reality with respect to geometry and exposure time and with a "best judgement" choice of densities for each operation, the calculation programmes have tended to overestimate the measured values of the total dose by a factor 4 to 6 , i.e. about an order of magnitude. It seems reasonable to state that the use of 'enveloping' scenarios, which necessarily cover a wide range of scenarios in connection with the calculation of clearance levels, would tend to accentuate this tendency of overestimation of dose uptake in most individual cases of recycling by melting by, say, one or even more orders of magnitude higher than those actually taken.

\section{INTRODUCTION}

For the nuclear industry, the minimisation of the volumes of radioactive waste arising from the refurbishment or decommissioning of nuclear facilities has been a high priority goal. The recycling of very low level radioactive material (or its reuse or disposal) without radiological restrictions, instead of disposal as radioactive waste, has long been identified as a significant means of achieving this aim. For regulators, it is important to develop guidance for recycling that adequately protects human health and the environment. Various international and national bodies such as the International Atomic Energy Agency, the European Commission, the US Nuclear Regulatory Commission have put forward proposals or guidance documents to regulate the "clearance" of this surplus material from regulatory control, in order to allow its recycling as a material management practice.

All these proposals are based on predicted scenarios for subsequent utilisation of the released materials. The calculation models used in these scenarios tend to utilise conservative data regarding exposure times and dose uptake as well as other assumptions as a safeguard against uncertainties.

Another aspect is common to all these calculation models and codes: none of them has ever been validated by comparison with the actual real life practice of recycling. The Swedish Radiation Protection Institute initiated the Validation Project in order to validate some of the assumptions made in these calculation models, and, thereby, better assess the radiological consequences of recycling on a practical large scale.

The validation was proposed to be carried out by the following chain of operations:

- Two consignments of contaminated scrap, each of about 30 tons, were to be melted at Studsvik RadWaste, Sweden.

- Ingots resulting from this melting, which have decayed to activity concentrations below release levels established by Swedish authorities, were to be transported to Åkers AB, 
Sweden. At Åkers AB, the ingots were to be remelted in the Åkers commercial foundries, along with uncontaminated scrap, for future use in the manufacture of rolls.

- The radiation doses to workers and other parameters were to be measured (1) during the operations at Studsvik, (2) during transport of the released ingots to Åkers, and (3) during the remelting of the ingots (along with other scrap) and manufacture of rolls from the resulting steel.

- The doses were also to be estimated using the RESRAD-RECYCLE and the CERISE programmes.

- A report was to be prepared comparing the measured radiation doses with those predicted by the calculations.

\section{PARTICIPANTS IN THE PROJECT}

The project was a co-operation between the following organisations:

- Swedish Radiation Protection Institute (SSI) initiated the project and is responsible for the central project management and for work not normally within the operational scope of the other partners. SSI constitutes the radiation protection and regulatory authority in Sweden.

- Studsvik RadWaste AB (Sweden) has a facility, in a radiologically controlled area, for melting contaminated metal scrap. The resulting ingots are allowed to decay. Afterwards, the ingots are used as feed material and mixed with uncontaminated scrap for remelting at commercial foundries.

- Akers AB (Sweden) is a major manufacturer of rolls for both hot and cold rolling in the international steel and non-ferrous metal industries. It is a customer of ingots produced at Studsvik RadWaste AB.

- The United States Department of Energy (USDOE), which has a large number of surplus nuclear facilities, the decommissioning of which will result in a considerable amount of recyclable material. The Department is therefore interested in validating calculation programmes used in connection with the clearance of material from regulatory control.

- Argonne National Laboratory (USA) developed the RESRAD-RECYCLE code under the sponsorship of the United States Department of Energy (USDOE). The code assesses the radiological doses for workers and the public, resulting from exposure to radionuclides in recycled metal with residual radioactivity.

- Institute de Radioprotection et Securité Nucléaire, IRSN, (France) has developed the CERISE code for the dose uptake through different pathways when an individual is exposed to ionising radiation. IRSN is an advisor to the radiation protection authorities in France.

- Belgoprocess (Belgium) is developing a process of milling very low level contaminated concrete, with a view to recycling it without radiological restrictions. The company is participating as an observer in order to study the possibility of a validation project for the RESRAD-RECYCLE and CERISE codes for concrete.

- Studsvik Stensand is a nuclear and other services company within the Studsvik group. Among the services it provides are health physics supervision as well as radiological measurements and analysis.

- Menon Consulting AB, which has been responsible for the project management and coordination of the various activities within the project. 


\section{EXECUTION OF THE PROJECT}

The actual execution of the project was slightly different from that originally planned. The first phase (melting of contaminated scrap at Studsvik, release of ingots and transport to Åkers) was carried out. The ingots were re-melted along with other (uncontaminated) scrap at Åkers to be used for manufacturing rolls. The doses to workers were measured at Studsvik, Åkers and during ingot transport.

Dose calculations were made in parallel with these operations using the RESRAD-RECYCLE and CERISE programmes. However, the results of these calculations could not be compared with the corresponding values of doses taken by workers, because all of the doses were below the limit of detection.

Originally, it was not the aim of the project to make a comparison between the two calculations programmes as such. However, as both programmes were used on the same input basis, it was possible to make certain comparisons.

Due to the fact that there were no detectable doses during the execution of the first phase of the project, it was decided that Phase 2 of the project should involve the melting of scrap with significantly higher levels of activity, instead of being a repetition of Phase 1 . This was achieved by studying the melting of a stainless steel fuel rack for the purpose of volume reduction. The activity concentration was about $160 \mathrm{~Bq} / \mathrm{g}$, mostly Co-60. The occurrence of detectable doses enabled a comparison between calculated and measured doses.

The fuel rack was melted in the Studsvik facility in the middle of January 2001, in the presence of project team including the dose modellers. Their presence and the discussions that were held in connection with the Phase 2 operation helped to model the calculations in accordance with the operations at Studsvik.

\section{OVERVIEW OF MEASUREMENTS AND CALCULATIONS DURING PHASE 1}

\section{Measurements}

The measurement campaigns during Phase 1 consisted of:

- Background measurements at Åkers. Measurements at Åkers during 'normal' melting of scrap (without Studsvik ingots);

- Measurements at Åkers during a melt with addition of Studsvik ingots;

- Background measurements during transportation between Studsvik and Åkers;

- Measurements during transport of ingots from Studsvik to Åkers;

- Background measurements at Studsvik new melting facility;

- Dose rate measurements at Studsvik during a complete cycle of melting of radioactive scrap (receipt/segmenting/storage/melting/storage).

The background radiation in the Åkers plant and the scrap yard was 200-300 cps (where $1 \mathrm{cps}$ is approximately equal to $1 \mathrm{nSv} / \mathrm{h}$ for Co 60), with a few exceptions where higher levels (700-800 cps) were noted. These slightly elevated areas of activity are probably due to the use of slag from earlier times in building material. No measurable doses over average background (150$200 \mathrm{nSv} / \mathrm{h}$ ) were observed adjacent to the furnace during the normal melting activities (i.e., 
without Studsvik ingots). Traces of Ra-226 and Th-232 were found in the slag and dust from furnace ventilation.

During these background measurements, an interesting piece of information was identified: the paint used to coat the moulds for the manufacture of rolls contained $3500-5500 \mathrm{~Bq} / 1$ of Ra-226 $(85 \%)$ and Th-232 (15\%). Air sampling revealed no detectable alpha or beta activity. No detectable activity levels were observed during the whole body monitoring of the personnel involved in these operations.

Measurements were also carried out at Åkers during the melting of 24 tons of steel including 7.5 tons of Studsvik ingots with an average activity of $0.4 \mathrm{~Bq} / \mathrm{g}$ Co-60. The resulting material had an average content of $0.15 \mathrm{~Bq} / \mathrm{g}$ Co- 60 .

The on line dose rate measurement adjacent to the furnace showed a slightly higher dose rate: 150-250 nSv/h compared to $150-200 \mathrm{nSv} / \mathrm{h}$ during 'normal' melting without Studsvik ingots. The background in the rest of the plant was normal, i.e. 200-300 cps. The personal air filter analysis showed the same level of Cs-137 as during normal melting.

During the transport of 30 tons of ingot (average activity concentration $0.4 \mathrm{~Bq} / \mathrm{g}$ ), there was no measurable difference in the dose to the driver, with ingots on the 1.25-hour trip from Studsvik to Åkers or empty on the trip back.

The Studsvik melting facility was brand new, while the cutting hall had been in service for five years, which explains the 300-350 cps background dose rate in the cutting hall, compared to the 200-250 cps in the newer areas. There were considerably higher levels in the neighbourhood of the slag binding product (400 cps), stampmass for the furnace $(700 \mathrm{cps})$, new insulation $(600 \mathrm{cps})$ and the new asphalt outside the plant (700 cps).

On-line dose rate measurements were made in the door between the cutting and melting halls. About seven tons of scrap was melted in three melts during a total of about 8.5 hours. During the first five hours, the dose rate varied between 0.3 and $0.4 \mu \mathrm{Sv} / \mathrm{h}$. During the next three hours, there were two periods of dose rates up to $0.6 \mu \mathrm{Sv} / \mathrm{h}$. There are no direct explanations for this from the melting process point of view.

None of the personnel involved took detectable doses above the limit for registration (i.e. $>$ $0.1 \mathrm{mSv}$ ) during the operations.

\section{Calculations}

In the phase I calculations, five scenarios representative of the main working posts in the Studsvik facility were considered. Thirty tons of scrap steel were loaded to the Studsvik induction furnace in 10 three-ton batches and melted. After the melting, the slag material was poured out, cooled, and handled by a slag worker. The steel melt remaining in the furnace was placed in large containers, cooled, and cast into ingots. The solid ingots were subsequently transported to a commercial facility for further processing. Radionuclides considered in dose calculations were Co-60, Zn-65, Sr-90, Tc-99, Cs-137, Am-241, U-238, Pu-239, and Ac-227, each treated separately at an activity concentration of $1 \mathrm{~Bq} / \mathrm{g}$.

Dose calculations were conducted for five different activities in the Studsvik facility: (1) sorting and cutting scrap metal after its reception; (2) scrap melting, excluding slag work; (3) slag 
handling; (4) ingot handling, including transfer and storage of ingot products; and (5) ingot transport. Five scenarios were developed to evaluate the doses to various workers: (1) scrap processor, who sorted and cut scrap metal into smaller pieces for melting, (2) furnace operator, who loaded the scrap metal to the furnace and operated the furnace, (3) slag worker, who removed the slag material from the top of the melt surface with a special tool and put it in a metallic box for cooling, (4) ingot caster, who poured the melt into moulds, moved the moulds for cooling, and removed the solid ingot from the moulds, and (5) ingot truck driver, who transported the solid ingots to Åkers for further processing.

RESRAD-RECYCLE and CERISE used the same mass partitioning factors: $90 \%$ for ingot, $1 \%$ for baghouse dust, and 10\% for slag, for dose calculations. The radionuclide partitioning factors used in dose calculations were different for the two codes.

With one exception, exposure pathways considered for each of the five activities were external radiation, inhalation, and ingestion. For the ingot truck driver, only the external radiation pathway was considered.

To model external radiation exposure, the radiation source was simulated by a full or half cylinder with dimensions (radius and thickness) representing the source geometry. An external dose conversion factor for each scenario was calculated on the basis of the dimensions of the cylindrical source, the exposure distance, and the density of the source material. Attenuation of external radiation was considered for the ingot truck driver scenario, resulting from the shielding of the truck cab.

Best judgement assumptions were made of the inhalation rate and the respirable fraction of the airborne dust. The dust loading factor and concentration of radionuclides in the dust varied according to the source material for the respective operation, e.g. scrap material for scrap processors, slag for slag workers, etc.

Both calculation programmes assumed an incidental ingestion of dust particles, with radionuclide concentrations at the same levels as for inhalation. The RESRAD-RECYCLE calculations assumed, in addition, that inhaled particles larger than of respirable size, would be ingested.

The inhalation and ingestion dose conversion factors used in the RESRAD-RECYCLE calculations were obtained from FGR No. 11 (Eckerman et al. 1988). Dose conversion factors used in CERISE calculations were obtained from the EU Basic Safety Standards (Council Directive 96/29/EURATOM). The external dose conversion factors calculated by the two computer codes were obtained by assuming the same geometry and exposure distances; however, the mathematical models used were different.

Because of these differences in the external radiation models of the two calculation codes, the external dose conversion factors are different, generally within a factor of 2 except for the two beta emitters, Sr-90 and Tc-99. The RESRAD-RECYCLE results for those radionuclides are much larger than the CERISE results.

Differences in the external dose results are caused by differences in the external dose conversion factors and differences in the radionuclide partitioning factors. The ratio of the dose results (RESRAD-RECYCLE/CERISE), if adjusted by the ratio of the dose conversion factor and the ratio of the radionuclide partitioning factor, are very close to 1 . The only exceptions are the adjusted ratios for $\mathrm{Zn}-65$ for the ingot handling and ingot transport scenarios. 
For the inhalation pathway also, there was agreement between the calculation code results, using the same dose conversion and radionuclide partitioning factors, except in the case of Zn-65 for the ingot handling scenario.

The ingestion pathway results show understandable differences due to the RESRAD-RECYCLE assumption of the ingestion of inhaled dust particles larger than of respirable size. If normalised, the RESRAD-RECYCLE/CERISE adjusted ratio is very close to 1 when the inhalation route of exposure is insignificant compared with the incidental ingestion route of exposure (e.g. the reception worker and ingot handling worker scenarios). When the inhalation route of exposure becomes more significant, the value of the adjusted ratio become larger. For the melting worker and slag worker, the adjusted ratios are close to 1.5 for all the radionuclides considered. A difference that cannot yet be explained is the small value (about 0.1 ) of the adjusted ratio for $\mathrm{Zn}$ 65 for the ingot handling and ingot transport scenarios.

\section{OVERVIEW OF EXECUTION, MEASUREMENTS AND CALCULATION DURING PHASE 2}

\section{Execution}

The main result of the Phase 1 activities was that the primary aim of the validation exercise, i.e., comparison of actual doses taken by workers with corresponding values calculated by the codes, could not be realised: the doses were, in every case, below the limits of detection. A different approach was therefore used for Phase 2, which had originally been planned to be a repetition of Phase 1. Instead it was decided to melt an object with high enough activity to give detectable doses to workers.

The chosen object was a stainless steel fuel rack from a Swedish nuclear power plant, which had been packed into a 20 foot container. The maximum dose rate on the outside of the container was $0.2 \mathrm{mSv} / \mathrm{h}$. The rack had a total mass of 3.4 (metric) tons. Nuclide specific measurements (made from outside the package) indicated an average radioactivity content of $109 \mathrm{kBq} / \mathrm{kg}$, mostly Co60. It was expected that such a concentration should give a surface dose of about $50 \mu \mathrm{Sv} / \mathrm{h}$ on the ingots after melting. The surface dose rates on the racks before melting would be significantly higher. This implied that the personnel engaged in the various stages of the melting operations would be exposed to measurable doses.

The rack was delivered in the container to Studsvik. Normally, the operations comprising the melting process consist of the following:

- Reception of package/unpacking;

- Segmenting of racks (plasma torch);

- Storage of segmented pieces;

- Melting;

- Slag handling;

- Filter dust handling;

- Handling and transport of ingots;

- Storage of ingots. 
In the treatment of the fuel rack, the segmented pieces were taken directly for melting, the filter dust quantity was too small to be collected and "handled" and storage of the ingots was not considered.

The truck drivers transported the container with the fuel rack into the melting facility at Studsvik. The scrap unloaders unloaded the fuel rack from the transport vehicle. The scrap cutters/sorters dissembled the fuel rack and cut it into smaller pieces that could be fed to the furnace. The cutting process produced a small quantity of swarf. The furnace operators loaded the fuel rack to the furnace and operated the furnace. After the ingot melt was poured into vertical moulds, the ingot handlers A moved the ingot (in moulds) away for cooling. After cooling, ingot handlers B removed the solid ingots from moulds. The solid ingots were then put on wooden pallets in a storage area by the ingot fork driver. During melting of the fuel rack, slag from the melt surface was removed by the slag handler with a special tool and was put in a metallic box in the same area for further processing.

\section{Measurements}

All personnel involved in the project operations were equipped with electronic (display) dosimeters. In order to make direct comparisons with the calculations, the electronic dosimeters were provided with dose codes corresponding to various operations, as follows:

Dose code 610: Transport of container into workshop.

Dose code 611: Opening of container, lifting of fuel rack, removing of plastic foil wrapping, setting up rack for cutting.

Dose code 612: Segmenting of fuel rack (plasma torch).

Dose code 613: Melting, slagging, pouring into moulds.

Dose code 614a: Handling of ingots in moulds (i.e. shielded).

Dose code 614b: Handling of ingots after cooling and removal from moulds (i.e. unshielded).

Dose code 615: Transport of ingots.

Dose code 617: Slag handling.

The measurements showed that segmenting was the work operation that gave the highest dose, almost $65 \%$ of the total dose incurred, while melting itself accounted for only about $13 \%$.

\section{Calculations}

To facilitate dose calculations, the geometry of the radiation source, exposure distance between the source and the worker, and the time span of each operation were developed on the basis of the real operations. All the parameter values used in the dose calculations were based on the Studsvik values except for the inhalation and ingestion dose conversion factors, for which the FGR values and the European Directive values were used by RESRAD-RECYCLE and CERISE, respectively.

Eight exposure scenarios were developed to account for the various operations conducted during the melting process. These eight scenarios evaluated doses to the following work groups: (1) scrap truck drivers, (2) scrap unloaders, (3) scrap cutters/sorters, (4) furnace operators, (5) ingot handlers A (during ingot cooling in moulds), (6) ingot handlers B (after ingot cooling and removal from moulds), (7) ingot fork driver, and (8) slag handler. 
Mass partitioning factors used in dose calculations were developed from the measured masses of the ingot product, the slag product, and filter dust and with application of the principle of mass conservation. The cutting swarf $(2 \mathrm{~kg})$ was neglected in RESRAD-RECYCLE and CERISE calculations because its mass was very small compared with the mass of the fuel rack. The partitioning factors used by RESRAD-RECYCLE were $98.35 \%$ for ingot, $1.64 \%$ for slag, and $0.01 \%$ for filter dust. The partitioning factors used by CERISE were $98.3 \%$ for ingot, $1.65 \%$ for slag, and $0.004 \%$ for filter dust.

Radionuclide partitioning factors used for dose calculations were developed on the basis of the measured activity contents in ingot, slag, and dust filters. Like the calculations for mass partitioning factors, for RESRAD-RECYCLE dose calculations, the measured radionuclide contents in the cutting swarf were neglected and subtracted from the total contents. For CERISE dose calculations, the partitioning factors were calculated by normalising the radionuclide content in ingot, slag, and filter dust, respectively, with the total content of radionuclides (including those in the cutting swarf).

Radionuclide concentrations in the fuel rack were calculated from information on total mass and amount of radionuclides in the three melting products. Concentrations in the fuel rack were calculated as $157 \mathrm{~Bq} / \mathrm{g}$ for Co-60, 3.66 Bq/g for Sb-125, $0.027 \mathrm{~Bq} / \mathrm{g}$ for Cs-134, $10.82 \mathrm{~Bq} / \mathrm{g}$ for Cs-137, and 0.0060 Bq/g for Eu-154.

Exposure pathways considered for dose calculations were external radiation, inhalation, and ingestion. For the ingot handler and ingot fork driver, radiation exposures from the inhalation and ingestion pathways were insignificant because little dust loading occurred during the operations. For the other scenarios, exposures from inhalation and ingestion were considered through the use of an inhalation rate of $1.2 \mathrm{~m}^{3} / \mathrm{h}$ and an ingestion rate of $0.00625 \mathrm{~g} / \mathrm{h}$.

The source geometries and exposure parameters used by RESRAD-RECYCLE and CERISE for dose calculations were similar for the various operations, except in the case of the ingot handler and ingot fork driver, where different source dimensions were used by the two codes. This difference was due to different perceptions regarding representing a radiation source of five ingots with a cylindrical geometry.

For the scrap truck driver scenario, the external radiation was considered to be attenuated by the truck cab. During the handling of ingot melt, ingot handlers A were shielded from radiation by the moulds, while ingot handlers B were unshielded. The slag handler was shielded by the slag container. The ingot fork driver took five ingots to storage at a time; therefore, dimensions of the radiation source were developed to consider potential radiation exposure from the five ingots.

The internal dose conversion factors used in RESRAD-RECYCLE calculations were obtained from FGR 11; those used in CERISE calculations were obtained from European Directive. Dose conversion factors for external radiation were calculated by the two codes.

Among the three exposure pathways analysed, radiation exposure from the external radiation pathway was far more significant than radiation exposure from the two internal radiation pathways (inhalation and ingestion). Radiation exposures incurred by the scrap unloaders and scrap cutters/sorters were greater than those incurred by the other workers because of the closer exposure distances and longer exposure times experienced by the scrap unloaders and scrap cutters/sorters. 
External radiation doses calculated by RESRAD-RECYCLE were smaller than those calculated by CERISE for the scrap truck drivers, scrap unloader, and scrap cutter/sorter. For the furnace operator and ingot handler scenarios, in contrast, RESRAD-RECYCLE results were greater than CERISE results. For the ingot fork driver and slag handler, dose results from the two codes were about the same. Larger differences were observed for the two ingot handling scenarios because of different geometries and dimensions assumed in the dose calculations.

\section{COMPARISON OF CALCULATIONS WITH MEASUREMENTS / CONCLUSIONS}

Table A shows a comparison of the RESRAD-RECYCLE and CERISE calculation results with the electronic dosimeter measurements for each dose code. The table has been divided into doses taken during work preparatory to melting and doses taken during and after melting.

Some comments on the table:

- Significant measured doses are noted only for the following scenarios: unloading of the fuel rack (611) and its cutting (612) and for the melting operations (613). For the other scenarios, measured doses are given but these are very low due to the short duration of work station activity (fuel rack transport into the building, ingot and slag handling, ingot truck transport).

- The part sum of doses shows that the pre-melting preparatory work accounted for $84 \%$ of the total doses, while the melting itself with ingot and slag handling were responsible for the remaining $16 \%$.

- There is an overestimation by the codes for the doses under dose codes 611,612 and $614 \mathrm{~b}$, covering $86 \%$ of the total dose; and an underestimation of the doses under codes 613 and 617.

The comparison of the calculation results indicates that, even with a carefully controlled reflection of reality with respect to geometry and exposure time and with a "best judgement" choice of densities for each operation, the calculation programmes have tended to overestimate the measured values of the total dose by a factor 4 to 6 , i.e. about an order of magnitude. An obvious explanation is the fact that the workers are not static, they move about constantly, changing the geometry, thus not taking the assumed doses.

Other practical aspects difficult to reflect exactly in the calculations are:

- Modelling of the source geometry (during cutting);

- Estimation of the density (during cutting);

- Estimation of the mean distance to the source (during cutting and melting);

- Dimensions of the source (during cutting and melting);

- Estimation of shielding thickness (during melting). 
WM'03 Conference, February 23 - 27, 2003, Tucson, AZ

Table A. Phase 2: Comparison of Doses per Dose Code Between RESRAD-RECYCLE/CERISE and Electronic Dosimeter Measurements.

\begin{tabular}{|c|c|c|c|c|c|c|c|c|}
\hline \multirow[b]{2}{*}{ Code } & & \multirow[b]{2}{*}{$\begin{array}{l}\text { RESRAD- } \\
\text { RECYCLE }\end{array}$} & \multirow[b]{2}{*}{ CERISE } & \multicolumn{3}{|c|}{ MEASUREMENTS } & \multicolumn{2}{|c|}{$\begin{array}{l}\text { RATIOS TO MEAS. } \\
\text { (Excl Bg) }\end{array}$} \\
\hline & & & & Incl Bg & Excl Bg & Bg & $\begin{array}{l}\text { RESRAD- } \\
\text { RECYCLE }\end{array}$ & CERISE \\
\hline 610 & $\begin{array}{l}\text { Transport of container into } \\
\text { workshop }\end{array}$ & 2.5 & 4 & 1 & $<1$ & & & - \\
\hline 611 & Opening of container & 156 & 256 & 43 & 38 & 5.2 & 4.1 & 6.7 \\
\hline 612 & Segmenting & 536 & 812 & 121 & 107 & 13.9 & 5.0 & 7.6 \\
\hline Part sur & re. work preparatory to melting & 694.5 & 1072 & 165 & 145 & & 4.2 & 7.4 \\
\hline 613 & Melting (with shielding) & 4 & 1.7 & 32 & 22 & 10.1 & 0.18 & 0.08 \\
\hline $614 a$ & Handling of ingots in moulds & 0.1 & 0.02 & 1 & $<1$ & 0.1 & & - \\
\hline $614 b$ & $\begin{array}{l}\text { Handling of ingots after removal } \\
\text { from moulds }\end{array}$ & 22 & 4.3 & 4 & 4 & $<0.1$ & 5.5 & 1.1 \\
\hline 615 & Transport of ingots to storage & 0.1 & 0.1 & & & $<0.1$ & & - \\
\hline 617 & Slag handling & 1.3 & 1.3 & 2 & 1.8 & 0.2 & 0.7 & 0.7 \\
\hline Total & & 722 & 1080 & 204 & 173 & & 4.2 & 6.2 \\
\hline
\end{tabular}

All values in micromanSv $(\mathrm{Bg}=$ Background $)$. 
The codes assume a source with mass specific distribution of radioactivity $(\mathrm{Bq} / \mathrm{g})$, while, in most cases, the actual object has the corresponding total activity concentrated on its surface. This should lead to an underestimation of the dose uptake by the workers involved in segmenting. However, the conservatism of the above listed factors obviously more than compensates for this, as is shown by the overestimation of the doses in total by the codes.

It seems reasonable to state that the use of 'enveloping' scenarios, which necessarily cover a wide range of scenarios in connection with the calculation of clearance levels, would tend to accentuate this tendency of overestimation of dose uptake in most individual cases of recycling by melting. Taking into account the sensitivity of the modelling and the practical aspects listed above, the estimated doses can be, say, one or even more orders of magnitude higher than those actually taken.

It should be pointed out that the Phase 2 melting was performed on a typical reactor system component with only gamma emitters, with Co-60 and Cs-137 as the dominant radionuclides. The dose incurred was almost exclusively by external exposure. This is in agreement with the dose modelling results.

A side aspect of the execution of the Validation Project - specifically the background measurements - was the revelation of radioactivity in unexpected places: the paint used for the painting of moulds at Åkers (3-5 Bq/g), the slag binding product (twice background radiation), the stamp mass, insulation and new asphalt at the Studsvik furnace (all at three to four times background). This serves to illustrate the undetected omnipresence of radioactivity in the human habitat at dose rate levels considerably higher (up to $400 \%$ over background) than the levels (ca $1 \%$ over background) at which the currently proposed clearance criteria are based on.

Finally, it is important to note that the degree of overestimation (a factor of 4-6), as recorded in the validation project, is generally regarded as 'acceptable' by dose modellers. The results will most probably not lead to any revision or refinement of these codes. For the nuclear decommissioner and the other producers of large volumes of only slightly radioactively contaminated material, the clearance levels resulting from such a degree of conservatism can lead to huge amounts of material unnecessarily being condemned to burial as radioactive waste. Considering that most such producers transfer their costs to the public, it is society at large that will foot the bill for this exercise in conservatism. 